\title{
Pregnancy-associated Deaths: 31-year Experience
}

\author{
Koichi Yoneyama ${ }^{1}$, Atsuko Sekiguchi ${ }^{2}$, Takashi Matsushima ${ }^{1}$, Rieko Kawase ${ }^{3}$, \\ Akihito Nakai ${ }^{2}$, Hirobumi Asakura ${ }^{1}$ and Toshiyuki Takeshita ${ }^{3}$ \\ ${ }^{1}$ Department of Obstetrics and Gynecology, Nippon Medical School Musashi Kosugi Hospital \\ ${ }^{2}$ Department of Obstetrics and Gynecology, Nippon Medical School Tama Nagayama Hospital \\ ${ }^{3}$ Department of Obstetrics and Gynecology, Nippon Medical School Hospital
}

\begin{abstract}
Aim: The aim of the present study was to elucidate the clinical characteristics of pregnancy-associated maternal deaths.

Methods: We performed a retrospective analysis with medical records and autopsy reports of cases of pregnancy-associated deaths. We collected information on all maternal deaths related to pregnancy that occurred in 3 hospitals affiliated with Nippon Medical School in Japan from January 1, 1984, to December 31, 2014. Data analyzed were maternal age, past medical history, parity, gestational age, clinical signs and symptoms, cause of death, and maternal autopsy findings.

Results: A total of 26 maternal deaths occurred during the 31-year study period. Autopsies were performed for 16 patients $(61.5 \%)$. The 26 deaths included 19 (73.1\%) classified as direct maternal deaths and $7(26.9 \%)$ classified as indirect maternal deaths. The mean maternal age at death was $33.1 \pm 4.3$ years (range, 26-41 years). The highest percentage of women was aged 35 to 39 years (38.5\%). Of the 26 maternal deaths, $69 \%$ occurred at 32 to 41 weeks of gestation. In cases of direct maternal death, the leading causes were amniotic fluid embolism (7 cases, $27.0 \%$ of all deaths) and hemorrhage (6 cases, $23.1 \%$ of all deaths). In cases of indirect obstetric deaths, the causes included cardiovascular disorders, cerebrovascular disorders, sepsis due to group A streptococcal infection, and hepatic failure of unknown etiology.

Conclusions: Amniotic fluid embolism was the leading cause of maternal deaths and was followed by obstetric hemorrhage. To prevent and reduce the number of maternal deaths in Japan, further basic and clinical research on amniotic fluid embolism is required. (J Nippon Med Sch 2016; 83: 6-14)
\end{abstract}

Key words: amniotic fluid embolism, direct maternal death, maternal death, maternal mortality, pregnancy-associated deaths

\section{Introduction}

Maternal death is the most devastating event seen in obstetrics practice. The maternal mortality ratio is defined as the number of maternal deaths per 100,000 live births. This ratio is used as an overall quality indicator of national maternal health and can be used for international comparisons. Over the last 20 years the number of maternal deaths has declined worldwide by $34 \%{ }^{1}$. However, declines in developed countries have been limited. Recent reports show increases in maternal mortality in the United States and the Netherlands ${ }^{2-4}$.

In Japan, the maternal mortality rate has shown re- markable declines, with reported rates of 87.6 in 1965, 28.7 in $1975,15.8$ in 1985, 7.2 in 1995, and 4.1 in $2010^{5}$. In 2013, the Japan Society of Obstetrics and Gynecology announced an annual report by the subcommittee for the examination of causes of maternal death and their prevention ${ }^{6}$. This report showed that hemorrhage in the third stage of labor is the most frequent cause of maternal deaths in Japan.

To prevent future maternal deaths, individual cases of maternal death must be assessed. However, because maternal deaths are rare, insufficient information is available about the clinical signs and symptoms, causes of

Correspondence to Koichi Yoneyama, MD, PhD, Department of Obstetrics and Gynecology, Nippon Medical School Musashi Kosugi Hospital, 1-396 Kosugi-cho, Nakahara-ku, Kawasaki, Kanagawa 211-8533, Japan

E-mail: kyone@nms.ac.jp

Journal Website (http://www.nms.ac.jp/jnms/) 
death, and the timing of onset. In the present study, we aimed to elucidate the clinical characteristics of patients who had maternal deaths. We retrospectively analyzed 26 cases of maternal death that occurred in patients treated in 1 of 3 hospitals affiliated with Nippon Medical School, Japan, during a 31-year period.

\section{Materials and Methods}

We performed a retrospective case study analysis of maternal deaths related to pregnancy using medical records and autopsy reports. Maternal death is defined by the World Health Organization as the death of a woman while pregnant or within 42 days of the end of pregnancy ${ }^{7}$. Maternal deaths are categorized as direct, indirect, or fortuitous. Direct deaths are defined as those resulting from obstetric complications of the pregnant state, interventions, omissions, incorrect treatment, or from a chain of events resulting from the above ${ }^{7}$. Indirect deaths are defined as deaths caused not by direct obstetric causes but by a previously existing disease or a disease that developed during pregnancy and was aggravated by the physiological effects of pregnancy ${ }^{7}$. Late maternal death was defined as the death of a woman from direct or indirect obstetric causes more than 42 days but less than 1 year after the completion of pregnancy.

To elucidate the clinical characteristics of maternal deaths, we collected information on all maternal deaths related to pregnancy that occurred from January 1, 1984, to December 31, 2014, in 3 hospitals affiliated with Nippon Medical School in Japan. These cases were analyzed with respect to maternal age, past medical history, parity, gestational age, clinical signs and symptoms, cause of death, and maternal autopsy findings if applicable. We excluded deaths caused by a traffic accident or malignancy.

\section{Results}

A total of 26 maternal deaths occurred during the 31-year study period (Table 1). Autopsies were performed for 16 patients (61.5\%). The 26 deaths included 19 (73.1\%) classified as direct maternal deaths and 7 (26.9\%) classified as indirect maternal deaths. No late maternal deaths were identified.

At least 2 patients $(7.7 \%)$ apparently had previously existing diseases that caused or influenced their deaths. The first patient was a woman who died at 32 weeks of gestation and had primary pulmonary hypertension (case 10); she died of cardiac decompensation immediately after delivery. The second patient, who died at 24 weeks of gestation, presented with a ruptured dissecting aortic aneurysm associated with Marfan syndrome (case 21). Unfortunately, these preexisting medical conditions were not recognized until the patients became critically ill.

Regarding risk factors for maternal deaths, 2 women who died because of intracranial hemorrhage (cases 11 and 12) had family histories of cerebral aneurysm.

In 8 women $(30.8 \%)$, including 1 patient with ectopic pregnancy, deliveries were not performed. These 8 women presented with symptoms before 29 weeks of gestation, with the exception of 1 woman who died suddenly at 32 weeks of gestation from an amniotic fluid embolism (case 1). Of the 18 deliveries, 9 were cesarean sections, 4 were vacuum extractions, and 5 were noninstrumental vaginal deliveries. No deaths were directly caused by the operative procedure of a cesarean section. Three deaths were directly related to vaginal delivery: 1 case of hemorrhagic shock after removal of the placenta (placenta accreta) (case 20), 1 case of severe postpartum hemorrhage due to uterine inversion (case 25), and 1 case of massive retroperitoneal hematoma due to shoulder dystocia (case 24). Two perimortem procedures (1 cesarean section and 1 vacuum extraction) were performed following maternal cardiopulmonary arrest caused by amniotic fluid embolism; the 2 fetuses survived, although 1 had a neurological disturbance.

Regarding fetal/neonatal outcomes, 14 fetuses (53.9\%) died in utero, 1 neonate $(3.8 \%)$ died soon after birth, 1 neonate $(3.8 \%)$ survived with neurological damage, and 10 neonates (38.5\%) survived without neurological impairment.

The mean maternal age at death was $33.1 \pm 4.3$ years (range, 26-41 years) (Table 2). The highest number of deaths occurred in women aged 35 to 39 years (38.5\%), followed by women aged 30 to 34 years (34.6\%). The mean age of the 19 women who direct maternal deaths was $33.0 \pm 2.4$ years (range, 26-41 years), and the mean age of the 7 women who died due to indirect maternal deaths was $33.3 \pm 2.4$ years (range, 30-37 years).

Twelve $(46.2 \%)$ maternal deaths occurred at 37 to 41 weeks of gestation (Fig. 1). Of the 26 maternal deaths, $69 \%$ occurred at 32 to 41 weeks of gestation. After 31 weeks of gestation, the number of maternal deaths increased progressively. Fewer deaths occurred in the second trimester than in the first or third trimester.

The most common cause of the 19 direct maternal deaths was amniotic fluid embolism, which was present in 7 cases $(27.0 \%$ of all deaths) (Table 3$)$. In 6 of these 7 patients, amniotic fluid embolism was associated with 


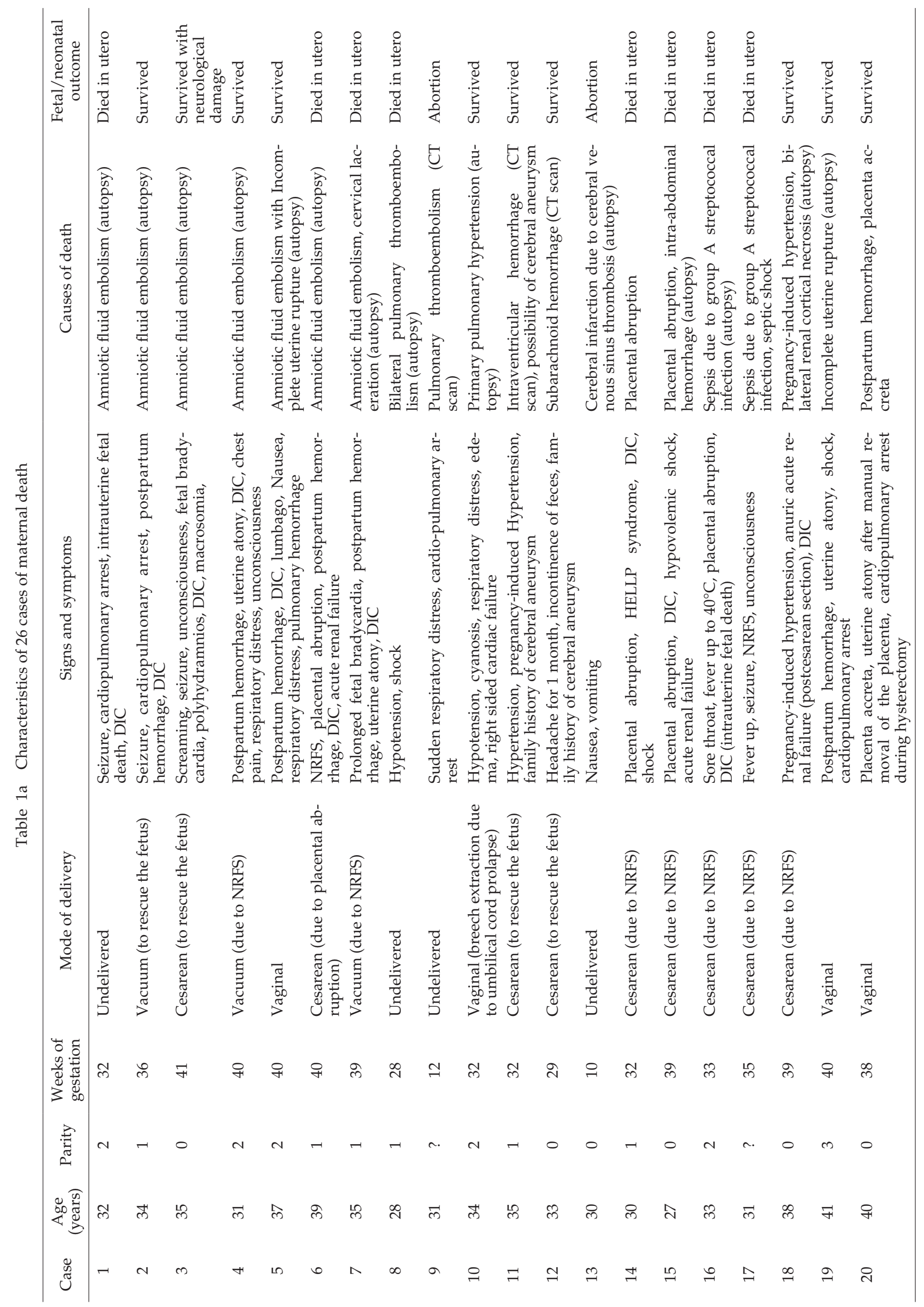




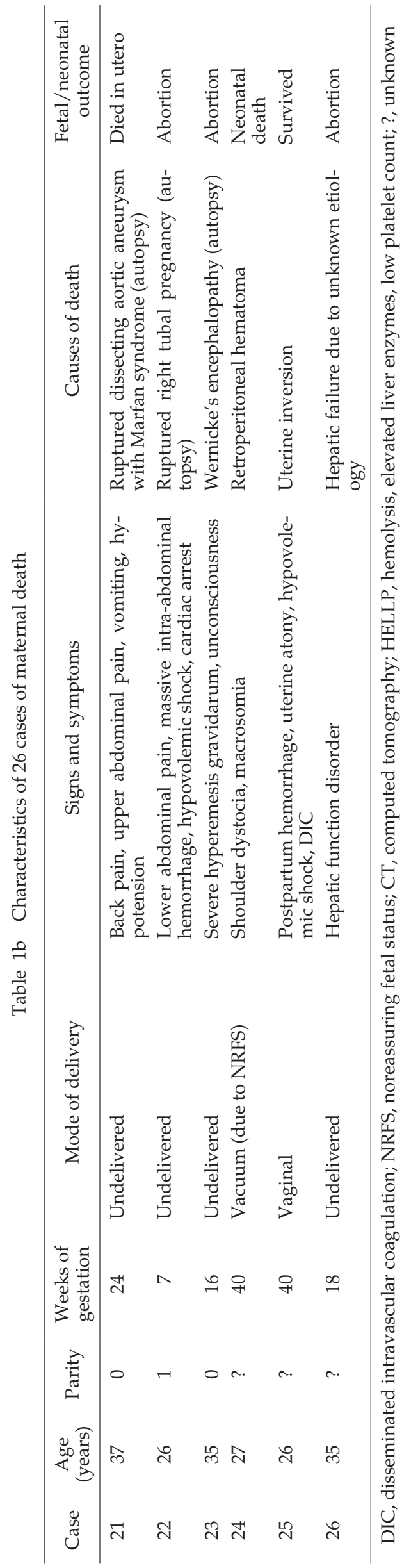

Table 2 Age at maternal death

\begin{tabular}{ccc}
\hline Maternal age (years) & Number & $\%$ \\
\hline $25-29$ & 5 & 19.2 \\
$30-34$ & 9 & 34.6 \\
$35-39$ & 10 & 38.5 \\
$40-44$ & 2 & 7.7 \\
\hline Total & 26 & 100 \\
\hline
\end{tabular}

disseminated intravascular coagulation. These 6 patients with amniotic fluid embolism also showed profound uterine bleeding as a presenting sign or a subsequent sign. The second most common cause of direct maternal death, with a total of 6 cases (23.1\% of all deaths), was hemorrhage and hematoma or both, including placental abruption ( 2 cases), incomplete uterine rupture (1 case), uterine inversion (1 case), uterine atony (1 case), and shoulder dystocia (1 case). The third most common causes of direct maternal death, with a total of 2 cases each $(7.7 \%$ of all deaths), were preeclampsia, which was associated with cerebral hemorrhage (1 case) or bilateral renal cortical necrosis (1 case), and pulmonary thromboembolism, which occurred at 28 and 12 weeks of gestation. No deaths due to pulmonary thromboembolism followed a cesarean delivery.

Also classified as direct maternal deaths were those of 1 patient (3.8\% of all deaths) with Wernicke's encephalopathy and 1 patient with a ruptured ectopic pregnancy.

The 7 indirect maternal deaths were caused by cardiovascular disorders (primary pulmonary hypertension in 1 case, dissecting aortic aneurysm with Marfan syndrome in 1 case), cerebrovascular disorders (cerebral infarction due to cerebral venous sinus thrombosis in 1 case, subarachnoid hemorrhage in 1 case), sepsis due to group $\mathrm{A}$ streptococcal infection (2 cases), and hepatic failure of unknown etiology (1 case).

The date of occurrence of the 29 maternal deaths was the first half (1984-1999) of the 31-year study period for 20 cases (77.0\%) (Fig. 2). No maternal deaths occurred in our hospitals from 2007 through 2014.

Three $(11.5 \%)$ of the 26 maternal deaths (cases 18, 22, and 24) were judged to have been potentially preventable by the adequate management of pregnancy-induced hypertension (case 18), the earlier detection of ectopic pregnancy (case 22), and cesarean section for macrosomia (case 24). 


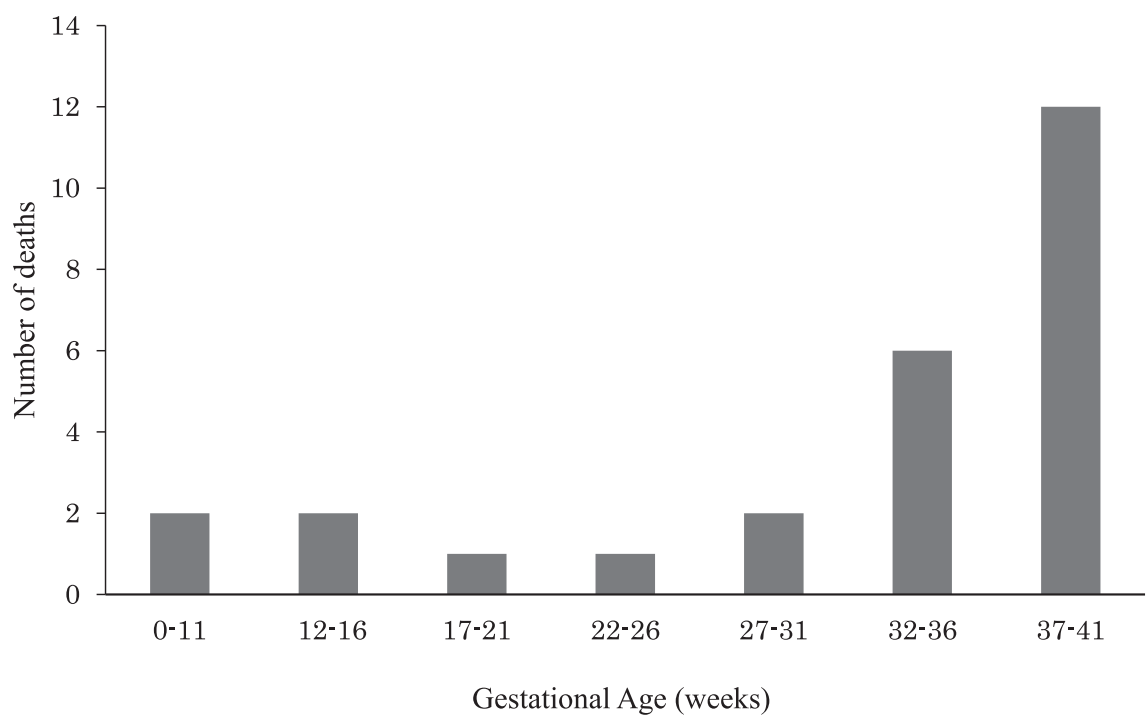

Fig. 1 Relationship between maternal death and gestational age Twelve (46.2\%) maternal deaths occurred at 37 to 41 weeks of gestation. Of all 26 maternal deaths, $69 \%$ occurred at 32 to 41 weeks of gestation. After 31 weeks of gestation, the number of maternal deaths increased progressively. Fewer deaths occurred in the second trimester than in the first or third trimester.

Table 3 Causes of maternal death, 1984-2014

\begin{tabular}{lcc}
\hline \multicolumn{1}{c}{ Cause of death } & Number & $\%$ \\
\hline Direct maternal (obstetric) death & $\mathbf{1 9}$ & 73.1 \\
Amniotic fluid embolism & 7 & 27.0 \\
Hemorrhage & 6 & 23.1 \\
$\quad$ Placental abruption & 2 & \\
Incomplete uterine rupture & 1 & \\
Uterine inversion & 1 & \\
Uterine atony after manual removal of placenta & 1 & \\
Shoulder dystocia & 1 & \\
Complications of preeclampsia & 2 & 7.7 \\
Cerebral hemorrhage & 1 & \\
Bilateral renal cortical necrosis (due to preeclampsia) & 1 & \\
Pulmonary thromboembolism & 2 & 7.7 \\
Wernicke's encephalopathy & 1 & 3.8 \\
Ectopic pregnancy & 1 & 3.8 \\
Indirect maternal (obstetric) death & 7 & $\mathbf{2 6 . 9}$ \\
Cardiovascular condition & 2 & 7.7 \\
Primary pulmonary hypertension & 1 & \\
Dissecting aortic aneurysm with Marfan syndrome & 1 & \\
Cerebrovascular disorder & 2 & 7.7 \\
Sepsis due to group A streptococcal infection & 2 & 7.7 \\
Hepatic failure & 1 & 3.8 \\
\hline$\quad$ Total & $\mathbf{2 6}$ & $\mathbf{1 0 0}$ \\
\hline
\end{tabular}

\section{Discussion}

We performed a retrospective analysis of 26 cases of pregnancy-related maternal deaths during a 31-year period in the affiliated hospitals of Nippon Medical School. Our study has 3 important findings. First, the leading cause of maternal deaths was amniotic fluid embolism and was followed by obstetric hemorrhage. Second, 69\% of all 26 maternal deaths occurred at 32 to 41 weeks of gestation. Third, risk factors for maternal death included a family history of cerebral aneurysm in 2 women who 


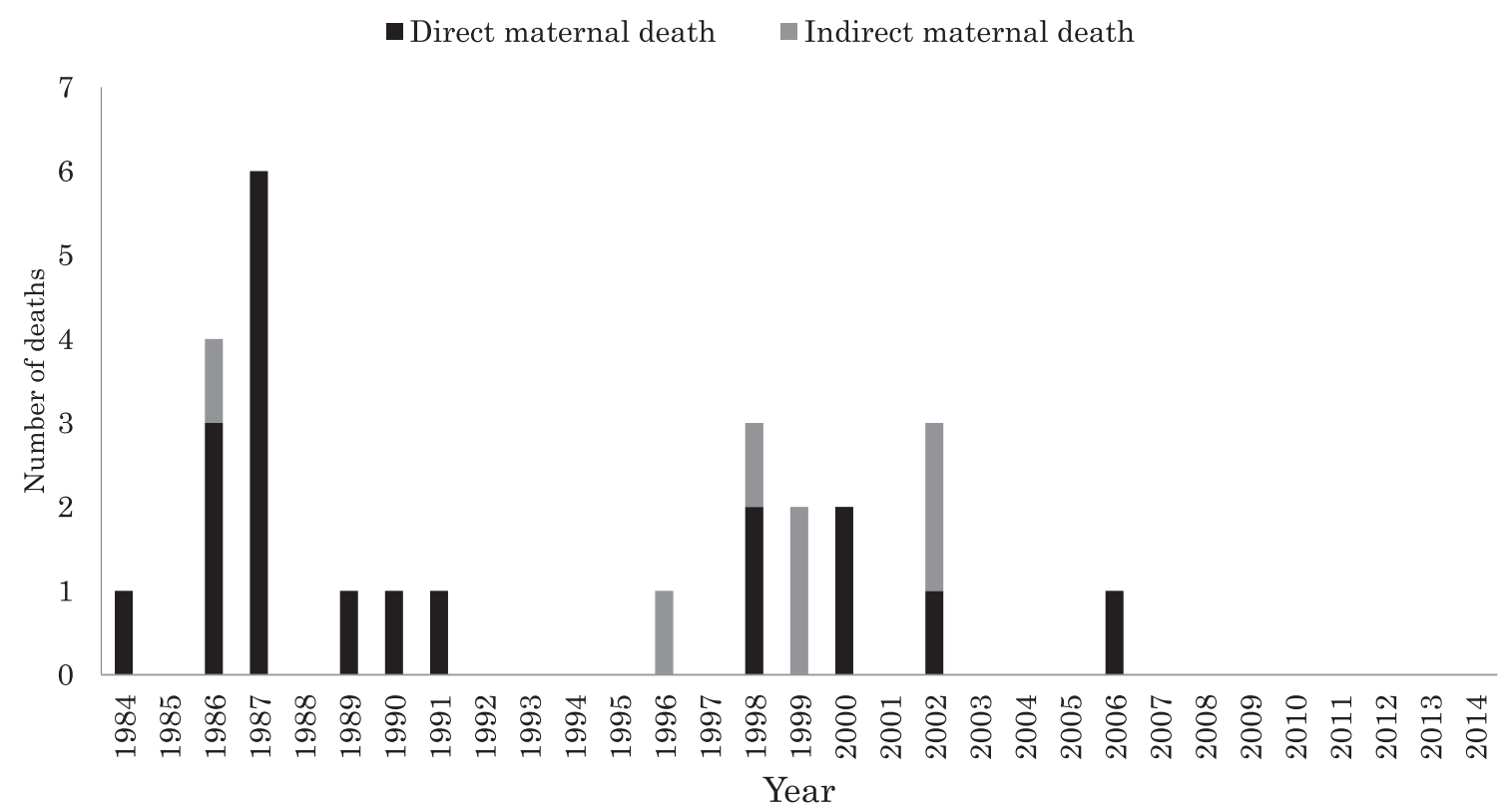

Fig. 2 Number of direct and indirect maternal deaths during a 31-year period.

Twenty (77.0\%) maternal deaths occurred in the first half (1984-1999) of the present study. From 2007 through 2014, no maternal deaths were observed in our hospitals.

died of intracranial hemorrhage.

Amniotic fluid embolism, the most common cause of maternal death in the present study, accounted for $27.0 \%$ of cases. The percentage of maternal deaths from amniotic fluid embolism we observed was higher than the percentages in other studies in developed countries $(13.1 \%-14.0 \%)^{2,8}$.

Recently, we reported a retrospective study of 10 patients with amniotic fluid embolism from the past 29 years. Seven of these 10 women died of amniotic fluid embolism?. These 7 cases of maternal death were also included and analyzed in the present study. In our previous study, we noticed a difficulty in diagnosing amniotic fluid embolism at an early stage. Amniotic fluid embolism was suspected in only 2 of the 10 patients at the time of onset. However, all 7 women who died underwent postmortem examinations, and amniotic fluid embolism was diagnosed on the basis of the detection of fetal elements in the maternal pulmonary vasculatures. The autopsies were critical for establishing correct diagnoses of amniotic fluid embolism. We assume that the high autopsy rate of $61.5 \%$ in the present study is the main reason many cases of amniotic fluid embolism were reported.

Kanayama et al. investigated causes of direct maternal deaths by examining 193 autopsy cases from 1989 through 2004 in Japan ${ }^{10}$. They also reported that amniotic fluid embolism was the most common cause of direct maternal deaths, accounting for $24.3 \%$ of cases. This rate is consistent with our rate of $27.0 \%$. The pathophysiology of amniotic fluid embolism remains poorly understood. To prevent and reduce the number of maternal deaths in Japan, further basic and clinical research on amniotic fluid embolism is required.

Our second key finding was that $69 \%$ of all 26 maternal deaths occurred during 32 to 41 weeks of gestation. After 31 weeks of gestation, the number of maternal deaths increased progressively. This finding is consistent with findings of previous studies ${ }^{8}$. We believe there are 3 possible explanations for this result. First, hemorrhage in the peripartum period is the major cause of maternal deaths. In a 2013 global study of worldwide maternal mortality, $24.6 \%$ of deaths occurred antepartum, $27.7 \%$ occurred intrapartum and immediately postpartum, and $35.6 \%$ occurred in the subacute and delayed postpartum period $^{11}$. Second, all 7 cases of amniotic fluid embolism, which was the leading cause of maternal deaths in the present study, occurred at 32 to 41 weeks of gestation. Third, we believe that hypervolemia associated with pregnancy is a reason for the progressive increase in the number of maternal deaths after 31 weeks of gestation.

The blood volume of cases of hypervolemia associated with normal pregnancy was an average of $40 \%$ to $45 \%$ greater than the nonpregnant blood volume after 32 to 34 weeks $^{12}$. Some women have only a modest increase in blood volume, but others have nearly a doubling of vol- 
$u^{12}$. Pregnancy-induced hypervolemia can trigger a critically ill pregnancy status. For example, a woman of the present study who died at 32 weeks of gestation had primary pulmonary hypertension (case 10). Until 30 weeks of gestation, she had no symptoms. After 30 weeks of gestation, cyanosis, respiratory distress, edema, and hypotension developed. At 32 weeks of gestation the woman was transferred to the intensive care unit of our hospital. A Swan-Ganz catheter was inserted, and hemodynamic measurements suggested marked pulmonary hypertension and right-sided cardiac failure. Despite intensive management, she died of cardiac decompensation immediately after the delivery of her child at 32 weeks of gestation. A postmortem examination confirmed the diagnosis of primary pulmonary hypertension.

Pregnancy-induced hypervolemia might have also affected our cases of intraventricular hemorrhage (case 11, 32 weeks), subarachnoid hemorrhage (case 12, 29 weeks), and ruptured dissecting aortic aneurysm (case 21, 24 weeks).

Recently, the results of a survey of pregnancyassociated intracranial hemorrhage in Japan were reported by the Stroke and Pregnancy Survey Committee of the Japan Neurosurgical Society ${ }^{13}$. Ninety-seven hemorrhagic strokes associated with pregnancy were analyzed. In this survey, 50\% of hemorrhagic strokes occurred after 32 weeks of gestation. Obstetricians should be aware of the increased risk of hemorrhagic stroke in the management of pregnant women, especially after 32 weeks of gestation.

Regarding risk factors for maternal death, we found that 2 women whose deaths were caused by intracranial hemorrhage had a family history of cerebral aneurysm. A history of aneurysmal subarachnoid hemorrhage in 2 or more first-degree relatives is reported to increase the lifetime risks of unruptured intracranial aneurysm and aneurysmal subarachnoid hemorrhage $e^{14-16}$. Therefore, screening for intracranial aneurysms should be considered for patients who have at least 2 first-degree relatives with aneurysmal subarachnoid hemorrhage according to guidelines from the European Stroke Organization and the American Heart Association ${ }^{14,17,18}$. In Japan, Okamoto and Horisawa have reported a case-control study of the relationship between family history and subarachnoid hemorrhage ${ }^{19}$. They showed that the risk of subarachnoid hemorrhage was elevated when (1) any first-degree relative had a positive episode of subarachnoid hemorrhage, (2) a mother or father had a relative with a positive episode of subarachnoid hemorrhage (an effect much greater in magnitude with a maternal rather than paternal history), and (3) any first-degree relative older than 50 years had a subarachnoid hemorrhage. They concluded that to prevent the onset of subarachnoid hemorrhage at a younger age, much more attention should be paid to individuals with any family members (first-degree relatives) who had episodes of subarachnoid hemorrhage.

In conclusion, we found that amniotic fluid embolism was the leading cause of maternal deaths, followed by obstetric hemorrhage. To prevent and reduce the number of maternal deaths in Japan, further basic and clinical research on amniotic fluid embolism is required. Of the 26 maternal deaths in our study, 69\% occurred during 32 to 41 weeks of gestation. We also noted the effect of pregnancy-associated hypervolemia. To prevent the onset of subarachnoid hemorrhage during pregnancy, much more attention should be paid to patients with any family members (first-degree relatives) who had episodes of subarachnoid hemorrhage or cerebral aneurysms.

Acknowledgements: We thank the clinician teams from the various centers participating in this study.

Conflict of Interest: The authors declare that they have no conflicting interests.

\section{References}

1. King JC: Strategies to reduce maternal mortality in developed countries. Curr Opin Obstet Gynecol 2013; 117-123.

2. Saucedo M, Deneux-Tharaux C, Bouvier-Colle MH: Ten years of confidential inquiries into maternal deaths in France, 1998-2007. Obstet Gynecol 2013; 122: 752-760.

3. Berg CJ, Callaghan WM, Syverson C, Henderson Z: Pregnancy-related mortality in the United States, 1998 to 2005. Obstet Gynecol 2010; 116: 1302-1309.

4. Schutte JM, Steegers EA, Schuitemaker NW, Santema JG, de Boer K, Pel M, Vermeulen G, Visser W, van Roosmalen J; Netherlands Maternal Mortality Committee: Rise in maternal mortality in the Netherlands. BJOG 2010; 117: 399406.

5. Midwifery in Japan. Japanese Nursing Association. http s://www.nurse.or.jp/jna/english/midwifery/pdf/mij201 4.pdf. Accessed November 11, 2015.

6. Masuzaki H, Unno N, Kanayama N, Ikeda T, Minakami H, Murakoshi T, Nakata M, Ishiwata I, Itoh H, Yoshida A: Annual report of Subcommittee for Examination of Causes of Maternal Death and their Prevention in Perinatology Committee, Japan Society of Obstetrics and Gynecology, 2013. J Obstet Gynaecol Res 2014; 40: 336-337.

7. World Health Organization, UNICEF, United Nations Population Fund, The World Bank: World Health Organization Library Cataloguing-in-Publication Data. In Trends in maternal mortality 1990 to 2008: estimates developed by WHO, UNICEF, UNFPA, The World Bank (World Health Organization, ed), 2010; pp 4-5, World Health Organization, Geneva. 
8. Clark SL, Belfort MA, Dildy GA, Herbst MA, Meyers JA, Hankins GD: Maternal death in the 21st century: causes, prevention, and relationship to cesarean delivery. Am J Obstet Gynecol 2008; 199: 36e1-5; discussion 91-92. e7-11.

9. Yoneyama K, Sekiguchi A, Matsushima T, Kawase R, Nakai A, Asakura H, Takeshita T: Clinical characteristics of amniotic fluid embolism: an experience of 29 years. J Obstet Gynaecol Res 2014; 40: 1862-1870.

10. Kanayama N, Inori J, Ishibashi-Ueda $H$, Takeuchi $M$, Nakayama M, Kimura S, Matsuda Y, Yoshimatsu J, Ikeda $\mathrm{T}$ : Maternal death analysis from the Japanese autopsy registry for recent 16 years: significance of amniotic fluid embolism. J Obstet Gynaecol Res 2011; 37: 58-63.

11. Kassebaum NJ, Bertozzi-Villa A, Coggeshall MS, Shackelford KA, Steiner C, Heuton KR, Gonzalez-Medina D, Barber R, Huynh C, Dicker D, Templin T, Wolock TM, Ozgoren AA, Abd-Allah F, Abera SF, Abubakar I, Achoki T, Adelekan A, Ademi Z, Adou AK, Adsuar JC, Agardh EE, Akena D, Alasfoor D, Alemu ZA, Alfonso-Cristancho R, Alhabib S, Ali R, Al Kahbouri MJ, Alla F, Allen PJ, AlMazroa MA, Alsharif U, Alvarez E, Alvis-Guzmán N, Amankwaa AA, Amare AT, Amini H, Ammar W, Antonio CA, Anwari P, Arnlöv J, Arsenijevic VS, Artaman A, Asad MM, Asghar RJ, Assadi R, Atkins LS, Badawi A, Balakrishnan K, Basu A, Basu S, Beardsley J, Bedi N, Bekele T, Bell ML, Bernabe E, Beyene TJ, Bhutta Z, Bin Abdulhak A, Blore JD, Basara BB, Bose D, Breitborde N, Cárdenas R, Castañeda-Orjuela CA, Castro RE, Catalá-López F, Cavlin A, Chang JC, Che X, Christophi CA, Chugh SS, Cirillo M, Colquhoun SM, Cooper LT, Cooper C, da Costa Leite I, Dandona L, Dandona R, Davis A, Dayama A, Degenhardt L, De Leo D, delPozo-Cruz B, Deribe K, Dessalegn $M$, de Veber GA, Dharmaratne SD, Dilmen U, Ding EL, Dorrington RE, Driscoll TR, Ermakov SP, Esteghamati A, Faraon EJ, Farzadfar F, Felicio MM, Fereshtehnejad SM, de Lima GM, Forouzanfar MH, França EB, Gaffikin L, Gambashidze K, Gankpé FG, Garcia AC, Geleijnse JM, Gibney KB, Giroud M, Glaser EL, Goginashvili K, Gona P, González-Castell D, Goto A, Gouda HN, Gugnani HC, Gupta R, Gupta R, Hafezi-Nejad N, Hamadeh RR, Hammami M, Hankey GJ, Harb HL, Havmoeller R, Hay SI, Pi IB, Hoek HW, Hosgood HD, Hoy DG, Husseini A, Idrisov BT, Innos K, Inoue M, Jacobsen $\mathrm{KH}$, Jahangir E, Jee $\mathrm{SH}$, Jensen PN, Jha V, Jiang G, Jonas JB, Juel K, Kabagambe EK, Kan H, Karam NE, Karch A, Karema CK, Kaul A, Kawakami N, Kazanjan K, Kazi DS, Kemp AH, Kengne AP, Kereselidze M, Khader YS, Khalifa SE, Khan EA, Khang YH, Knibbs L, Kokubo Y, Kosen S, Defo BK, Kulkarni C, Kulkarni VS, Kumar GA, Kumar K, Kumar RB, Kwan G, Lai T, Lalloo R, Lam $\mathrm{H}$, Lansingh VC, Larsson A, Lee JT, Leigh J, Leinsalu M, Leung R, Li X, Li Y, Li Y, Liang J, Liang X, Lim SS, Lin HH, Lipshultz SE, Liu S, Liu Y, Lloyd BK, London SJ, Lotufo PA, Ma J, Ma S, Machado VM, Mainoo NK, Majdan M, Mapoma CC, Marcenes W, Marzan MB, Mason-Jones AJ, Mehndiratta MM, Mejia-Rodriguez F, Memish ZA, Mendoza W, Miller TR, Mills EJ, Mokdad AH, Mola GL, Monasta L, de la Cruz Monis J, Hernandez JC, Moore AR, Moradi-Lakeh M, Mori R, Mueller UO, Mukaigawara M, Naheed A, Naidoo KS, Nand D, Nangia V, Nash D, Nejjari C, Nelson RG, Neupane SP, Newton CR, Ng M, Nieuwenhuijsen MJ, Nisar MI, Nolte $S$, Norheim OF, Nyakarahuka L, Oh IH, Ohkubo T, Olusanya BO, Omer SB, Opio JN, Orisakwe OE, Pandian JD, Papachristou C, Park JH, Caicedo AJ, Patten SB, Paul VK, Pavlin BI, Pearce N, Pereira DM, Pesudovs K, Petzold M, Poenaru
D, Polanczyk GV, Polinder S, Pope D, Pourmalek F, Qato D, Quistberg DA, Rafay A, Rahimi K, Rahimi-Movaghar V, ur Rahman S, Raju M, Rana SM, Refaat A, Ronfani L, Roy N, Pimienta TG, Sahraian MA, Salomon JA, Sampson U, Santos IS, Sawhney M, Sayinzoga F, Schneider IJ, Schumacher A, Schwebel DC, Seedat S, Sepanlou SG, Servan-Mori EE, Shakh-Nazarova M, Sheikhbahaei S, Shibuya K, Shin HH, Shiue I, Sigfusdottir ID, Silberberg DH, Silva AP, Singh JA, Skirbekk V, Sliwa K, Soshnikov SS, Sposato LA, Sreeramareddy CT, Stroumpoulis K, Sturua L, Sykes BL, Tabb KM, Talongwa RT, Tan F, Teixeira CM, Tenkorang EY, Terkawi AS, Thorne-Lyman AL, Tirschwell DL, Towbin JA, Tran BX, Tsilimbaris M, Uchendu US, Ukwaja KN, Undurraga EA, Uzun SB, Vallely $\mathrm{AJ}$, van Gool $\mathrm{CH}$, Vasankari TJ, Vavilala MS, Venketasubramanian $\mathrm{N}$, Villalpando $\mathrm{S}$, Violante FS, Vlassov VV, Vos T, Waller S, Wang H, Wang L, Wang X, Wang Y, Weichenthal S, Weiderpass E, Weintraub RG, Westerman R, Wilkinson JD, Woldeyohannes SM, Wong JQ, Wordofa MA, Xu G, Yang YC, Yano Y, Yentur GK, Yip $\mathrm{P}$, Yonemoto $\mathrm{N}$, Yoon SJ, Younis $\mathrm{MZ}, \mathrm{Yu} \mathrm{C}$, Jin $\mathrm{KY}, \mathrm{El}$ Sayed Zaki M, Zhao Y, Zheng Y, Zhou M, Zhu J, Zou XN, Lopez AD, Naghavi M, Murray CJ, Lozano R: Global, regional, and national levels and causes of maternal mortality during 1990-2013: a systematic analysis for the Global Burden of Disease Study 2013. Lancet 2014; 384: 9801004.

12. Cunningham FG, Leveno KJ, Bloom SL, Spong CY, Dashe JS, Hoffman BL, Casey BM, Sheffield JS: Maternal physiology. In Williams Obstetrics (Cunningham FG, Leveno KJ, Bloom SL, Spong CY, Dashe JS, Hoffman BL, Casey BM, Sheffield JS, eds), 2014; pp 46-100, McGraw-Hill Education, New York.

13. Takahashi JC, Iihara $\mathrm{K}$, Ishii $\mathrm{A}$, Watanabe $\mathrm{E}$, Ikeda $\mathrm{T}$, Miyamoto S: Pregnancy-associated intracranial hemorrhage: results of a survey of neurosurgical institutes across Japan. J Stroke Cerebrovasc Dis 2014; 23: e65-71.

14. Bor AS, Rinkel GJ, van Norden J, Wermer MJ: Long-term, serial screening for intracranial aneurysms in individuals with a family history of aneurysmal subarachnoid haemorrhage: a cohort study. Lancet Neurol 2014; 13: 385-392.

15. Bor AS, Rinkel GJ, Adami J, Koffijberg H, Ekbom A, Buskens E, Blomqvist P, Granath F: Risk of subarachnoid haemorrhage according to number of affected relatives: a population based case-control study. Brain 2008; 131: 2662-2665.

16. Vlak MH, Algra A, Brandenburg R, Rinkel GJ: Prevalence of unruptured intracranial aneurysms, with emphasis on sex, age, comorbidity, country, and time period: a systematic review and meta-analysis. Lancet Neurol 2011; 10: 626-636.

17. Steiner T, Juvela S, Unterberg A, Jung C, Forsting $M$, Rinkel G: European Stroke Organization guidelines for the management of intracranial aneurysms and subarachnoid haemorrhage. Cerebrovasc Dis 2013; 35: 93-112.

18. Connolly ES Jr, Rabinstein AA, Carhuapoma JR, Derdeyn CP, Dion J, Higashida RT, Hoh BL, Kirkness CJ, Naidech AM, Ogilvy CS, Patel AB, Thompson BG, Vespa P; American Heart Association Stroke Council; Council on Cardiovascular Radiology and Intervention; Council on Cardiovascular Nursing; Council on Cardiovascular Surgery and Anesthesia; Council on Clinical Cardiology: Guidelines for the management of aneurysmal subarachnoid hemorrhage: a guideline for healthcare professionals from the American Heart Association/American Stroke Association. Stroke 2012; 43: 1711-1737. 
19. Okamoto K, Horisawa R: Prediction of subarachnoid hemorrhage from a ruptured cerebral aneurysm by discriminant analysis in women. J Stroke Cerebrovasc Dis 2007; 16: 245-250.

(Received, May 16, 2015)

(Accepted, December 28, 2015) 